\title{
PERBANDINGAN PRODUKSI AIR MATA PADA PENGGUNA LENSA KONTAK DENGAN YANG TIDAK MENGGUNAKAN LENSA KONTAK
}

\author{
${ }^{1}$ Paulus Rocky Wakarie \\ ${ }^{2}$ Laya Rares
}

\begin{abstract}
Bagian Ilmu Kesehatan Mata Fakultas Kedokteran Universitas Sam Ratulangi Manado Email:rocky_roq@hotmail.com
\end{abstract}

\begin{abstract}
There are so many factor that can affect the healthiness of eye, and one of them is tears. However, there are many circumstancesthat can affect the production of tears and lead to discomfort in the eye and one of them is contact-lenswearing.The aim of this research is to know the difference of tear production between contact-lens wearer and non contact-lens wearer. The method of this research is cross sectional with characteristic observation. And the problems to identify is happen by it self without intervention from researcher. The samples is group 2010 - 2013 students of Medical Faculty of Sam Ratulangi University amount to 30 peoples (15 contact-lenswearer, 15 contact-lensnon-wearer) who take with random sampling. The results showmore female sample (24 sample) than male (6 sample) with mean age $19.3 \pm 2$. Comparisonof tear productionincontact-lens usersand non contactlens user was not significant $(p>0.05)$. From result we can conclude, difference of tear production between contact-lens wearer and non- contact-lens wearer is not significantly distinct.
\end{abstract}

Keywords:contact-lens wear, tear production.

Abstrak: Banyak factor yang mempengaruhi kesehatan mata, salah satunya adalah air mata. Namun, banyak keadaan yang dapat mempengaruhi produksi dari air mata ini sehingga bisa menimbulkan keluhan-keluhan pengelihatan, salah satunya adalah pemakaian contactlens.Tujuan dari penelitian ini adalah untuk mengetahui perbedaan produksi air mata pada pengguna contact-lens dengan yang tidak menggunakan contact-lens. Metode penelitian yang digunakan adalah potong lintang dengan sifat observational dan masalah yang diteliti terjadi dengan sendirinya tanpa intervasi dari peneliti. Sampel penelitian adalah mahasiswa FK UNSRAT angkatan 2010-2013 berjumlah 30 orang dimana 15 orang merupakan pengguna contact-lens dan 15 orang lain tidak menggunakan contact-lens yang diambil secara acak sederhana.Hasil penelitian menunjukkan sampe wanita (24 sampel) lebih banyak dari sampel laki-laki (6 sampel) dengan rata-rata umur 19,4 \pm 2 . Perbandingan produksi air mata pada pengguna contact-lens dengan yang tidak menggunakan contact-lens $(p>0,05)$ tidak terlalu signifikan. Kesimpulan perbandingan produksi air mata pada pengguna contact-lens dengan yang tidak menggunakan contact-lens tidak terlalu signifikan.

Kata kunci:penggunaan contact-lens, produksi air mata. 
Kesehatan mata merupakan suatu aspek yang penting dan harus dijaga demi memperoleh informasi yang diperlukan. Namun, banyak manusia yang mengabaikan bahkan tidak peduli pada kesehatan mata, sehingga dapat menimbulkan gangguan pada mata. $^{2}$

Salah satu gangguan pada mata adalah gangguan pada air mata, baik secara sekresi maupun ekskresi. Air mata merupakan suatu substansi yang sangat penting dalam menjaga kesehatan mata, karena selain untuk melicinkan permukaan kornea, air mata juga melindungi mata dari pertumbuhan bakteri-bakteri. Gangguan pada air mata sering disebut dry eye syndrome atau keratokonjungtivitis sica. ${ }^{3}$ Hal ini bisa disebabkan oleh banyak hal, salah satunya adalah penggunaan contactlens.

Contact lens induce dry eye merupakan suatu kumpulan gejala yang mengakibatkan ketidak-nyamanan pada mata. Gejala-gejala yang tersebut dimulai dari: (1) mata terasa panas, (2) mata terasa kering, (3) mata terasa seperti kemasukan benda asing, (4) mata terasa berpasir, (5) mata berair (6) mata merah. Penelitian menunjukan bahwa 50\% pengguna contactlens pernah mengalami dry eye syndrome $^{18,19}$.

Berdasarkan data NCBI, secara keseluruhan pengguna contact-lens di dunia mencapai 140 juta orang, baik contact-lens untuk kepentingan koreksi ataupun untuk kosmetik. Pengguna terbanyak terdapat di benua Asia dan Amerika, dimana 38 juta pengguna berasal dari Amerika Utara kemudian 24 juta pengguna berasal dari Asia dan 20 juta pengguna berasal dari Eropa. ${ }^{5}$ Untuk lama pemakaian, sekitar 60\% pengguna contact-lens menggunakan extended wear contact-lens, dan $40 \%$ pengguna contact-lens menggunakan daily wear contact-lens. ${ }^{6}$
Dari data di atas, contact-lens lebih menjadi pilihan masyarakat dalam menangani gangguan mata, khususnya dalam hal kelainan refraksi. Namun penggunaan contact-lens yang lebih modern tidak menghindarkan para penggunanya dari efek samping. Menurut Stanler, sekitar 80.000 pengguna contact-lens menderita penyakit mata, khususnya gangguan pada konjungtiva, kornea dan kalenjar air mata. ${ }^{5}$

\section{METODOLOGI}

Penelitian ini bersifat analitik komparatif dengan menggunakan desain potong lintang (cross sectional) dengan sifat observasional. Bahan yang digunakan adalah berupa hasil uji Schirmer Test 1 pada 30 pasang mata sampel.Penelitian dilaksanakan di Bagian Ilmu Kesehatan Mata Fakultas Kedokteran Universitas Sam Ratulangi Manado.Penelitian ini dilakukan pada bulan November 2013- Desember 2013.Subjek penelitian adalah 30 sampel mahasiswa Fakultas Kedokteran UNSRAT angkatan 2010-2013 dimana 15 orang pengguna contact-lens dan 15 orang tidak menggunakan contact-lens. Secara umum, variabel penelitian ialah usia, jenis kelamin, status penggunaan contact-lens, dan hasil Schimer test 1. Pada pengguna contact-lens variable penelitian ialah lama pemakaian, tujuan pemakaian, status konsultasi dokter, bahan contact-lens, jenis pemakain contactlens, masa pakai contact-lens, cara pakai contact-lens dan kuisioner keluhan CLIDE.

\section{HASIL PENELITIAN}

Berdasarkan pengumpulan data yang dilakukan selama bulan November 2013 , makadidapatkan 15sampel menggunakan contact lens. Hasil penelitian menunjukkan bahwa mayoritas sampel adalah wanita, yaitu 24 orang (80\%). Mayoritas sampel berumur 20 tahun, berjumlah 15 orang 50\%) (Tabel 1). 
Tabel 1. Distribusi frekuensi karakteristik

\begin{tabular}{ccc}
\hline Karakteristik & f (orang) & $\mathbf{\%}$ \\
\hline Jenis Kelamin & & \\
Laki-laki & 6 & 20 \\
Perempuan & 24 & 80 \\
\hline Total & $\mathbf{3 0}$ & $\mathbf{1 0 0}$ \\
\hline Umur & & \\
18 tahun & 5 & 16.7 \\
19 tahun & 10 & 33.3 \\
20 tahun & 15 & 50.0 \\
\hline Total & $\mathbf{3 0}$ & $\mathbf{1 0 0}$ \\
\hline sampel & &
\end{tabular}

Dari data penelitian, didapatkan 15 orang merupakan pengguna contact-lens (50\%) dan 15 orang tidak menggunakan contact-lens (Tabel 2).

Tabel 2. Distribusi frekuensi pengguna contact-

\begin{tabular}{ccc}
\hline Karakteristik & f (orang) & $\mathbf{\%}$ \\
\hline $\begin{array}{c}\text { Penggunaan } \\
\text { contact-lens }\end{array}$ & & \\
Ya & 15 & 50 \\
Tidak & 15 & 50 \\
\hline Total & $\mathbf{3 0}$ & $\mathbf{1 0 0}$ \\
\hline lens & &
\end{tabular}

Dari data penelitian, mayoritas sampel adalah pemakai contact-lens dengan lama pemakaianlebih dari 2 tahun, yaitu berjumlah 12 orang (80.0\%). Mayoritas tujuansampel yang menggunakan contactlens adalah sebagai alat bantu pengelihatan untuk mengoreksi kelainan refraksi, berjumlah 10 orang (66.7\%), dan mayoritas sampel tidak berkonsultasi terlebih dahulu dengan dokter ahli sebelum memutuskan menggunakan contact-lens, yaitu sebanyak 11 orang (73,3\%) (Tabel 3).

Tabel 3. Distribusi frekuensi karakteristik pengguna contact-lens

\begin{tabular}{ccc}
\hline Karakteristik & f (orang) & $\mathbf{\%}$ \\
\hline Lama Penggunaan & & \\
$<1$ tahun & 1 & 6.7 \\
$1-2$ tahun & 2 & 13.3 \\
$>2$ tahun & 12 & 80.0 \\
\hline Total & $\mathbf{1 5}$ & $\mathbf{1 0 0}$ \\
\hline $\begin{array}{c}\text { Tujuan } \\
\text { fashion }\end{array}$ & 5 & 33.3 \\
koreksi kelainan \\
refraksi & 10 & 66.7 \\
\hline$\quad$ Total & $\mathbf{1 5}$ & $\mathbf{1 0 0}$ \\
\hline $\begin{array}{c}\text { Status konsultasi } \\
\text { dengan dokter }\end{array}$ & & \\
$\quad \begin{array}{c}\text { Melakukan } \\
\text { konsultasi }\end{array}$ & 4 & 26.7 \\
$\begin{array}{c}\text { Tidak melakukan } \\
\text { konsultasi }\end{array}$ & 11 & 73.3 \\
\hline Total & $\mathbf{1 5}$ & $\mathbf{1 0 0}$ \\
\hline
\end{tabular}

Dari data penelitian, didapatkan gejala CLIDE yang paling banyak dikeluhkan oleh responden adalah mata terasa kering $(86,7 \%)$, sedangkan gejala yang paling sedikit yang dikeluhkan adalah mata terasa panas \& mata terasa berpasir (20\%) (Tabel 4). 
Tabel 4. Distribusi frekuensi gejala dry eye syndrome

Dari data penelitian, Hasil analisis bivariat antara produksi air mata dan penggunaan contact-lens didapatkan nilai $\mathrm{p}$ $(p=0,363)$ lebih besar dibanding nilai alpha $(a=0,05)$. Hal tersebut menunjukkan bahwa produksi air mata tidak berhubungan secara signifikan dengan penggunaan contact-lens (Tabel 5).

Tabel 5. Perbandingan produksi air mata dan penggunan contact-lens

\begin{tabular}{ccccccc}
\hline Penggunaan & \multicolumn{4}{c}{$\begin{array}{c}\text { Produksi Air Mata } \\
\text { (dalam satuan }\end{array}$ mm) } \\
\cline { 2 - 7 } & \multicolumn{4}{c}{$<$ 10 } & $\mathbf{1 0}-\mathbf{3 0}$ & \multicolumn{2}{c}{$>\mathbf{3 0}$} \\
Ya & 0 & 0 & 6 & 20 & 9 & 30 \\
Tidak & 4 & 13,3 & 3 & 10 & 8 & 26,7 \\
Total & $\mathbf{4}$ & $\mathbf{1 3 , 3}$ & $\mathbf{9}$ & $\mathbf{3 0}$ & $\mathbf{1 7}$ & $\mathbf{5 6 , 7}$ \\
\hline
\end{tabular}

\section{PEMBAHASAN}

Penelitian Barr et al (2005) menunjukan bahwa rata-rata pengguna lensa kontak di seluruh dunia sekitar 128 juta orang, dan sekitar 13,2 juta orang pengguna lensa kontak berusia antara 18 sampai 34 tahun. Di Indonesia sendiri pengguna contact-lens hanya $2 \%$ dari total jumlah penduduk ${ }^{4,16}$.

Penelitian Nathan et al (2012) menunjukan 107.209 pengguna contact-lens bahwa dari 39 negara yang disurvey, sekitar 88.729 orang menggunakan jenis pemakaian daily wear, yang di susul oleh pemakaian extended wear ${ }^{6}$. Menurut Dogru et all (2009) mayoritas pengguna contact-lens di seluruh dunia telah memakai contact-lens lebih dari 2 tahun $^{9}$.

Di Asia Pasifik, 50\% pengguna kacamata beralih ke contact-lens dimana 60\% pengguna contact-lens menggunakannya untuk membantu mengoreksi kelainan refraksi, menggantikan kacamata, sedangkan 40\% pengguna contact-lens hanya sebagai alat fashion ${ }^{16}$.

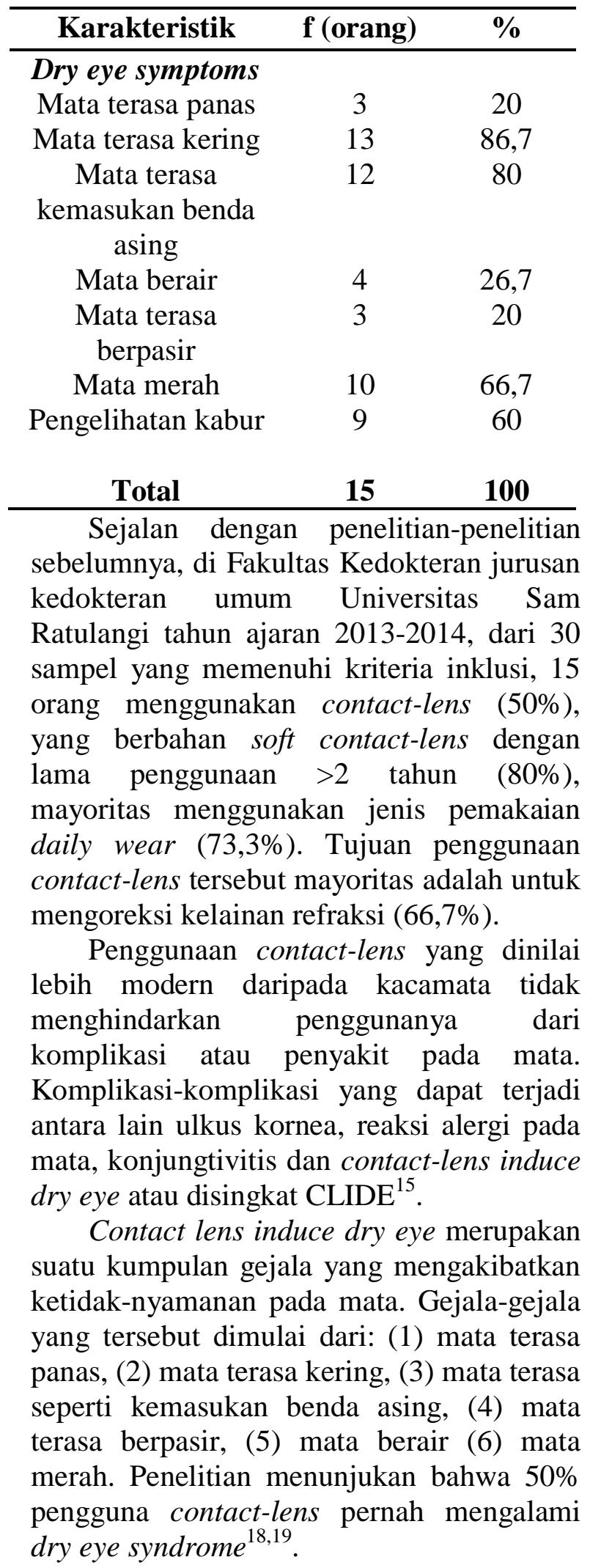


Menurut Shresta et all (2012), perempuan dilaporkan lebih sering mengalami dry eye syndrome. Selain itu, dilaporkan juga bahwa keluhan dry eye syndrome mulai muncul pada pengguna contact-lens dengan umur 22-29 tahun. Penggunaan contat-lens selama 6 bulan dikatakan sudah mampu untuk memicu terjadinya dry eye syndrome ${ }^{7}$.

Menurut Jason et all (2006), mayoritas pengguna contact-lens mengeluhkan mata terasa kering, terasa panas dan terasa seperti kemasukan benda asing. Rasa tidak nyaman ini membuat pengguna contact-lens memutuskan tidak menggunakan atau memberi jeda waktu kurang lebih 1 minggu hingga 1 bulan untuk tidak memakai contact-lens.

Dalam penelitian ini, keluhan yang paling banyak adalah mata terasa kering $(86,7 \%)$ dan mata terasa kemasukan benda asing (80,0\%).

Penelitian menunjukan bahwa contact-lens mempengaruhi produksi air mata. Pada saat seseorang menggunakan contact-lens, terjadi penipisan pada precorneal tear film, kerusakan pada lipid layer, peningkatan produksi mucus dan perubahan pada karakteristik dan jumlah kedipan mata ${ }^{20}$.

Menurut survey epidemiologi di USA, dari 415 pengguna contact-lens, factor yang paling berperan dalam contact lens induce dry eye adalah dikarenakan penipisan dari precorneal tear film $(\mathrm{p}=0,008)$ dan juga peningkatan dari osmolaritas dari air mata $(\mathrm{p}=0,05)^{21}$.

Pada penelitian ini, didapatkan perbedaan yang tidak signifikan pada produksi air mata pengguna contact-lens dengan yang tidak menggunakan contactlens, ini tidak sesuai dengan teori-teori yang di kemukakan oleh beberapa penelitian. Namun keluhan-keluhan yang berhubungan dengan CLIDE mulai dirasakan para pengguna contact-lens seperti mata terasa kering (86,7\%), mata terasa seperti kemasukan benda asing (80\%) dan mata merah (66,7\%).

\section{KESIMPULAN}

Dari hasil penelitian yang telah dilakukan, dapat disimpulkan bahwa penggunaan contact-lens mayoritas berjenis kelamin perempuan. Umur 20 tahun merupakan umur tersering yang menggunakan contact-lens. Dan . perbandingan produksi air mata pada pengguna contact-lens dengan yang tidak menggunakan contact-lens tidak terlalu signifikan.

\section{SARAN}

Sebelum memutuskan untuk menggunakan contact-lens, lebih baik berkonsultasi dengan dokter ahli untuk mengetahui lebih lanjut keadaan dari mata sehingga pada saat menggunakan contactlens tidak terjadi efek samping maupun komplikasi karena ketidak-cocokan keadaan mata dengan contact-lens.

\section{DAFTAR PUSTAKA}

1. Andriono GA. Kecacatan akibat kecelakaan kerja dan penyakit akibat kerja pada mata. [cited 2013Sept21]. Available from: http://www.jamsostek.co.id/content_file/ mata.pdf

2. Komite nasional penanggulangan gangguan pengelihatan dan kebutaan. Undang-undang No. 23 tahun 1992. Diunduh dari: http://PGPK.sisfo.net

3. Vaughan \& Asbury (2007) Oftalmologi Umum, 17 edn., jakarta: Penerbit Buku Kedokteran EGC.

4. Universitas Sumatera Utara (2012) Tingkat pengetahuan mahasiswa FK USU yang menggunakan lensa kontak terhadap dampak negatif penggunaannya angkatan 2007-2009, Available at: 
http://repository.usu.ac.id/bitstream/123 456789/67889/4/Chapter\%20II.pdf

5. Universitas Kristen Maranatha Bandung (2012) Pemeriksaan bakteriologis terhadap cairan perawatan lensa kontak, Available at: http://0910138/Chapter1 repository.maranatha.edu/3419/3/091013 8/chapter1.pdf

6. Efron.N, Morgan Philip B. ,Woods Craig A. International Survey of Contact Lens Prescribing for Extended Wear. 2010. American Academy of Oftometry

7. Shresta, G.S., Sijakhu, D., Shrestha, J.B., Shrestha, J.K. (2012) ", Tearfilmevaluation in contact lens wearers and non wearers, 34(2),pp. 1

8. Mark DP Willcox, Jenny Lan (1999) ", Secretory immunoglobulin-A in tears: functions and changes during contact lens wearer, 82(1), pp. 1

9. Dogru, M., Ward SK, Wakamatsu T, Ibrahim O, Schnider C, Kojima T, Matsumotot Y, Ogawa J, Shimazaki J, Tsubota K (2011) ", Theeffect of 2 week senofilicon-A silicone hydrogel contact lens daily wear on tear function and ocular surface health status, 34(2), pp. 77-82.99

10. Gary N. Foulks, MD, FACS (2012) Contact lens induce dry-eye, Available at:

http://www.eyecareeducators.com/site/c ontact_lens_induced_dry_eye.htm (Accessed: 23 September 2013).

11. Ilysa H.S (2010) Ilmu penyakit mata, 3 edn., Jakarta: Balai Penerbit FKUI

12. Universitas Sumatera Utara (2012) Pengaruh asap rokok pada kesehatan mata, Available at: http://repository.usu.ac.id/bitstream/123 456789/67889/4/Chapter\%20II.pdf

(Accessed: 23 September 2013).

13. Eyedocs.co.uk (2012) Schirmer's test, Available at: http://www.eyecareeduhttp://www.eyedo cs.co.uk/ophthalmology- learning/articles/cornea/505-schirmerstestcators.com/site/contact lens induced dry_eye.htm (Accessed: 23 September 2013).

14. Encyclopaedia Britannica Inc.. Contact lens.

http://www.britannica.com/EBchecked/t opic/134628/contact-lens (accessed 23 September 2013).

15. Universitas Sumatera Utara (2012) Lensa Kontak, Available at: http://repository.usu.ac.id/bitstream/123 456789/22688/4/Chapter\%20II.pdf (Accessed: 23 September 2013).

16. Tekno Kompas. Lensa kontak sekali pakai lebih sehat. http://tekno.kompas.com/read/2011/10/3 0/16040287/lensa.kontak.sekali.pakai.le bih.sehat (accessed 13 January 2014).

17. Muralidran Tiarasan, H. Syaiful Bahri . Tingkat pengetahuan pemakaian lensa kontak dalam kalangan mahasiwa FK USU Stambuk 2009 dan 2011. EJournal FK USU.2013;1(1):2

18. J.J. Nichols. Tear film, contact lens, and patient-related factors associated with contact lens-related dry eye. http://www.iovs.org/content/47/4/1319.s hort (accessed 14 January 2014).

19. all about vision. Dry Eye Syndrome. http://www.allaboutvision.com/condition s/dryeye.htm (accessed 14 January 2014).

20. AOCLE. Contact Lens Associated Dry Eye.

http://www.aocle.org/livingL/cla_dryeye html (accessed 24 January 2014).

21. DEWS Epidemiology. The epidemiology of dry eye disease. DEWS Epidemiology.2007;5(2):93-106. 